\title{
BIDIRECTIONAL FUNCTION OF SHENGHE POWDER ON REPAIR OF RADIATION- INDUCED DNA DAMAGE IN GLIOMA AND ASTROCYTE
}

\section{Yuesheng Xia, ${ }^{1}$ Yongqi Li, ${ }^{* 1}$ Jianhua Wang, ${ }^{1}$ Huan Wang, ${ }^{2}$ Jing Kang, ${ }^{3}$ Baoying Wang ${ }^{3}$ and Zengxia $\mathrm{Hou}^{4}$}

\author{
${ }^{1}$ Xijing Hospital, Fourth Ministry Medical University, Xi'an City, Shaanxi Province, 710032, \\ China. ${ }^{2}$ Shanxi College of Traditional Chinese Medicine, Taiyuan City, Shanxi Province, 030024, \\ China. ${ }^{3}$ Shanxi Province People's Hospital, Taiyuan City, Shanxi Province, 030012, China. ${ }^{4}$ Changhai \\ Hospital, Second military Medical University, Shanghai City, 200433, China. \\ *E-mail: hsiayuer@hotmail.com, Yongqi133@yahoo.com.cn
}

\begin{abstract}
The study assessed the effect of Chinese herbs of Shenghe Powder (SHP) on the repair capacity of gamma-radiation-induced DNA damage in rat glioma cells (C6) compared with normal human astrocytes (NHA). C6 and NHA Cells treated with SHP and irradiated with 2Gy of gamma radiation. Cells growth inhibition were analysed by MTT assay, DNA damage and repair were evaluated using phosphorylated histone $\mathrm{H} 2 \mathrm{AX}(\gamma \mathrm{H} 2 \mathrm{AX})$ at the appointed time. Apoptosis was observed by flow cytometry, and the expression of DNA-dependent protein kinase (DNA-PK) and surviving proteins were assessed by Western blot analysis. SHP depressed the radiation-induced DNA double-strand break and enhanced the DNA repair capacity in NHA, which correlated with promotion of DNA-PK phosphorylation. In contrast, SHP enhanced radiosensitivity of $\mathrm{C} 6$ cells, the pre-treatment with SHP resulted in reduced numbers of $\gamma \mathrm{H} 2 \mathrm{AX}$ foci in irradiated C6 cells, and decreased the expression of DNA-PK and survivn $(\mathrm{P}<0.005)$. It significant effect on inhibition of C6 cell proliferation and induced C6 cells apoptosis in a time-depdendent manner than radiation alone $(\mathrm{P}<0.001)$. SHP showed a novel bidirectional function to improve the radioresistance of NHA and enhanced radiosensitivity of C6 cells. This implies that SHP can protect the NHA from radiant damage and enhanced the sensitivity of C6 cells to radiation, which could be attributed to the alteration of survivin DNA-PK in DNA repair processes.
\end{abstract}

Keywords: DNA repair, radiation, glioma, astrocyte, Chinese herbs

\section{Introduction}

High-grade glioma is common in primary malignant brain tumor, standard therapy consists of surgical resection followed by radiotherapy, despite the use of conventional therapeutic modalities, the prognosis in patients is very poor (Fogh et al., 2010; Arslan et al., 2006). Attempts to improve outcome by increasing the local radiation dose have in general been unsuccessful because of necrosis in the surrounding brain, which becomes dose limiting before significant improved local tumor control is achieved. On conventional radiation dose, the development of resistance of glioma to radiation is a major problem during the treatment of tumors (Clarke et al., 2009; Stupp et al., 2007). Obviously, a more effective approach would be to develop agents that selectively sensitize these glioma cells to radiation. Studies approved DNA damage and repair capability related to radiation-induced cytotoxicity and radiosensitivity (Manti and D'Arco, 2010). In this study, we examined DNA damage responses and repair in rat glioma cell lines (C6) and normal human astrocytes (NHA) treated with Shenghe powder (SHP) and radiation, and attempted to demonstrate its mechanism. 


\section{Materials and Methods}

\section{Materials}

Rat glioma cells was purchased from the Second Military Medical University, normal human astrocytes were purchased from Cambrex Bio Science (Wokingham, UK). 3-[4,5-dimethylthiozol-2-yl]-2,5-diphenyltetrazolium bromide (MTT, Sigma Chemicals, St Louis, MO), anti- $\gamma \mathrm{H} 2 \mathrm{AX}$ antibody (Upstate Biotechnology, USA), Survivin antibody (Novus biological, Littleton, CO, USA), DNA-dependent protein kinase (DNA-PK) antibody (Upstate Biotechnology, Lake Placid, NY). SHP mainly includes Radix Ginseng, Scrophularia ningpaensis Heml, Atractylodes macrocephala Koidz, Lacrymajobi Linn. var. ma-yuen (Roman.) Stapf, Herba Hedyotis Diffusae, Herba Cistanches, Bufo gargarizans, and Glycyrhiza uralensis Fisch. All Chinese herbs were purchased from Shanxi Company of Chinese Herbal Medicines and identified by professor Yuesheng Xia.

\section{Methods \\ SHP Extraction Method}

Previously described methods was used (Wang et al., 2007). The dried whole herbs (1000g) were degreased by heating under reflux with industrial ethanol in a bath and then extracted 3 times with $10 \mathrm{~L}$ boiling distilled water for $1 \mathrm{hr}$ each time. The decoctions were then filtered through carbasus, mixed, and concentrated to $1000 \mathrm{ml}$. The concentrated extract was mixed with $95 \%$ ethanol to make the ethanol content up to $80 \%$. After standing overnight (20 $2 \mathrm{~h}$ ), the precipitate was filtered, washed, and vacuum-dried to give a brown power. Before experimentation, it was dissolved in phosphate-buffered saline (PBS) and filtered with a $0.22-\mu \mathrm{m}$ membrane. The percolate was made up to concentrations of $1.0 \mathrm{mg} / \mathrm{l}$ and stored at $-20^{\circ} \mathrm{C}$.

\section{Cell Culture}

C6 and NHA cells were grown in RPMI 1640 (Life Technologies, Inc., Rockville, MD) containing glutamate (5mM) and $5 \%$ fetal bovine serum, and maintained at $37{ }^{\circ} \mathrm{C}$ in an atmosphere of $5 \% \mathrm{CO}_{2}$ and $95 \%$ room air.

\section{SHP Treatment and Irradiation}

The exponentially grown cell lines C6 and NHA were treated with SHP (1mg/l) for $2 \mathrm{hr}$. Then, culture plates were cooled on ice and irradiated with $0 \sim 2 \mathrm{~Gy}$ of gamma radiation at a dose rate of $0.78 \mathrm{~Gy} / \mathrm{min}$ (137cesium irradiator, Atomic Energy, Ottawa, Canada). SHP was not removed from the medium. After irradiation, the NHA and C6 cell lines were placed back into the incubator $\left(37^{\circ} \mathrm{C}\right)$ and the kinetics of DNA repair was assessed, control cells were subjected to similar treatment but without irradiation or SHP.

\section{MTT Assays}

C6 and NHA Cells were plated in a 96-well plate and treated with lower concentrations of SHP (1mg/l), and some were exposed to radiation. After treatment, cells were stained with MTT, and incubated for $4 \mathrm{hr}$ in a $37{ }^{\circ} \mathrm{C}$ incubator. Then the cells were lysed in $150 \mu \mathrm{L}$ of ethanol/DMSO mixture $(1: 1)$, and the absorbance read at $540 \mathrm{~nm}$ using a 96 -well plate reader. 


\section{Immunofluorescent Analysis for $\gamma \mathrm{H} 2 \mathrm{AX}$}

An approach similar to method of Camphausen et al. (2004) was adopted. C6 and NHA cells were cultured on coverslips placed in 35-mm dishes. Fractional cells were exposed to $1 \mathrm{mg} / \mathrm{l} \mathrm{SHP}$ for $24 \mathrm{hr}$ at $37{ }^{\circ} \mathrm{C}$, after which time the cells were rapidly washed three times with PBS and the cells incubated in fresh medium for 30 min to allow time for phosphorylation of histone $\mathrm{H} 2 \mathrm{AX}$. Other cells were were exposed to $1 \mathrm{mg} / \mathrm{l} \mathrm{SHP}$ for $2 \mathrm{hr}$ at $37{ }^{\circ} \mathrm{C}$ and then irradiated with 0 , 1, or $2 \mathrm{~Gy}$ and incubated for a further $30 \mathrm{~min}$. The medium was removed, and the cells were washed with PBS and then held in methanol/PBS (50:50 v/v) at room temperature for $10 \mathrm{~min}$ before fixing them in methanol at $-30{ }^{\circ} \mathrm{C}$ for $30 \mathrm{~min}$. After removal of the methanol, the cells were held in PBS at room temperature for 5 min and then blocked with 5\% milk powder in PBS for $30 \mathrm{~min}$. The cells were then stained with antiphospho-histone $\mathrm{H} 2 \mathrm{AX}$ antibodies for $1.5 \mathrm{hr}$ at room temperature in the dark. After removal of the primary antibody, the cells were washed with PBS, followed by $0.1 \%$ Tween 20 in PBS and three more times with PBS, and then incubated with Alexa Fluor 488-labeled goat anti-mouse IgG antibody (Molecular Probes, Eugene, OR) at room temperature in the dark for $45 \mathrm{~min}$. The cells were again washed with PBS, followed by $0.1 \%$ Tween 20 in PBS and three more times with PBS and rinsed with water. The coverslips were mounted on microscope slides with $4 \mu 1$ mounting solution $(1 \mathrm{mg} / \mathrm{ml}$ p-phenylenediamine, $3 \mu \mathrm{g} / \mathrm{ml}$ 4',6-diamidino-2-phenylindole [DAPI], $90 \%$ glycerol in PBS) and stored at $4{ }^{\circ} \mathrm{C}$ in the dark. Fluorescent foci were imaged with a Zeiss LSM510 Laser Scanning Confocal microscope (Carl Zeiss, Jena, Germany) mounted on a Zeiss Axiovert 100M microscope. Images were captured by a Photometrics Sensys CCD camera (Roper Scientific) and imported into IP Labs image analysis software package (Scanalytics, Inc.). For each treatment condition, $\gamma \mathrm{H} 2 \mathrm{AX}$ foci were determined in at least 300 cells.

\section{Western Blot Assay}

Lysates were generated by placing these cells in RIPA lysis buffer (for Suvivin) or Chaps Lysis buffer (for DNA-PK). Western blotting assays were performed to determine total protein concentrations, which were normalized to $1 \mu \mathrm{g} / \mu \mathrm{l}$ for all samples. Samples were then prepared in sample buffer and heated to $95{ }^{\circ} \mathrm{C}$ for $5 \mathrm{~min}$. Protein lysates $(15 \mathrm{ml})$ in sample buffer from each tissue were loaded within each well. Gels were run at constant current (40 mA) for 3-4 hr for maximum separation. Wet transfer was performed for $4 \mathrm{hr}$ at constant voltage $(40 \mathrm{~V})$ using polyvinylidene difluoride membrane presoaked in methanol. The membrane was blocked in $5 \%$ milk in $0.2 \%$ tetrabutyl antimony (TBST). The membrane was then washed in $0.2 \%$ TBST $\times 3$ for 15 min each. The membranes were then incubated overnight with primary antibodies directed at survivin and DNA-PK. Subsequently, the membranes were washed in $0.2 \%$ TBST $\times 3$ for 15 min each. The membrane was then incubated with secondary antibody for $45 \mathrm{~min}$. Chemiluminescent (Bio-Rad, Hercules, CA, USA) detection was then used to detect expression of survivin, DNA-PK, respectively. For each gel, positive and negative controls were loaded for survivin or DNA-PK, respectively. Actin levels served as internal loading controls.

\section{Measurement of Apoptosis}

Annexin-V Staining

Phosphotidylserine exposure on the outer layer of the cell membrane was measured using the binding of annexin V-fluorescein isothiocyanate (FITC). Cells were harvested and washed with cold PBS, incubated for 15 min with annexin V-FITC and propidium iodide and analyzed by flow cytometry (Becton Dickinson, Franklin Lakes, NJ, USA). 


\section{Flow Cytometric Analysis}

Cells were grown in 6-well plates and were treated as indicated. Then, attached and floating cells were pooled, pelleted by centrifugation, washed in PBS, and fixed with cold $70 \%$ ethanol containing $0.5 \%$ Tween 20 at $4{ }^{\circ} \mathrm{C}$ overnight. Cells were washed and resuspended in $1.0 \mathrm{ml}$ of propidium iodide solution containing $100 \mathrm{lg}$ of $\mathrm{RNase} \mathrm{A} / \mathrm{ml}$ and $50 \mu \mathrm{g}$ propidium iodide/ml and incubated for $30 \mathrm{~min}$ at $37{ }^{\circ} \mathrm{C}$. Apoptotic cells were assayed using FACSort Becton Dickinson Flow Cytometer at $488 \mathrm{~nm}$ and data were analyzed with CELLQuest Software. Cells with sub-G1 propidium iodide incorporation were considered as apoptotic. The percentage of apoptotic cells was calculated as the ratio of events on sub-G1 to events from the whole population.

\section{Statistical Analysis}

Data are presented as mean $( \pm \mathrm{SD}$, or SE). Mean values were compared by the Student's $\mathrm{t}$ test. The threshold of statistical significance was set at $P<0.05$. Statistical analyses were performed using SPSS 17.0 package (SPSS, Chicago, IL, USA).

\section{Results \\ Proliferation Assay}

C6 and NHA cells were treated with SHP at a 1mg/l, $24 \mathrm{hrs}$ before single-dose irradiation ( 0,1 or $2 \mathrm{~Gy})$.The MTT assay was used to determine the effect of SHP on C6 and NHA cell survival and proliferation at $0,2,4$, and 6 days after cell irradiation. As figure 1 showed, both cell lines when irradiated, but not treated with SHP, showed a time-dependent decrease in cell survival and proliferation compared with cells that received no radiation $(\mathrm{P}<0.005)$, the $\mathrm{C} 6$ cell line seemed more radioresistant than the NHA cell line. NHA cell lines treated with SHP and radiation showed a time-dependent decrease in cell proliferation before 2 day, which gradually presented radio-resistance compared with cells that received radiation alone after 2 day $(\mathrm{P}<0.005)$ (Figure 1A). Figure 1 displayed the largest decline in cell survival which occurred between 2 and 4 days after radiation. Both cell lines treated with SHP did result in an opposite results. C6 proliferation and cell viability decreased significantly after SHP, the greatest decrease in cell survival and proliferation occurred in the fourth day (P < 0.001). In contrast, NHA treated with SHP reversed the shape of the time-dependent decrease curve and upgraded the curve. It shows that SHP may inhibit the repair of DNA damage in C6 and enhance the repair of DNA damage in NHA.

\section{H2AX Phosphorylation in Glioma and Normal Astrocytes Cells}

Immunofluorescence was used to visualize and quantify phosphorylated H2AX foci in C6 and NHA cells at various times after irradiation in vitro. These foci are thought to represent sites of DNA double-strand breaks (DSBs) where chromatin structural change is occurring. H2AX phosphorylation is recognized to be an early event in break repair and has a role in subsequent recruitment of repair proteins. Foci resolution is thought to occur following DSBs repair, and persistent foci at late time points are thought to represent residual unrepaired DSBs (Mah et al.,2010; Entin-Meer et al., 2007). By comparing the number of foci per cell across the dose range of interest over a repair time from $30 \mathrm{~min}$ to $24 \mathrm{hr}$, we can compare induction and resolution of DSBs and therefore define DSBs repair kinetics in these cell lines.

We used the assay in the C6 and NHA cells examined at $0.5,4,8$, and $24 \mathrm{hr}$ after irradiation, when resolution of foci was occurring. These data are expressed as foci resolution with time; a representation of DSBs repair kinetics is shown in 
Figure 2. Clearly much higher amounts of $\gamma \mathrm{H} 2 \mathrm{AX}$ foci were observed in NHA control group and C6 treated group. All cells tested showed radiation dose-dependent increase in residual $\gamma \mathrm{H} 2 \mathrm{AX}$ foci reflecting unrepaired DNA double-strand breaks.

A

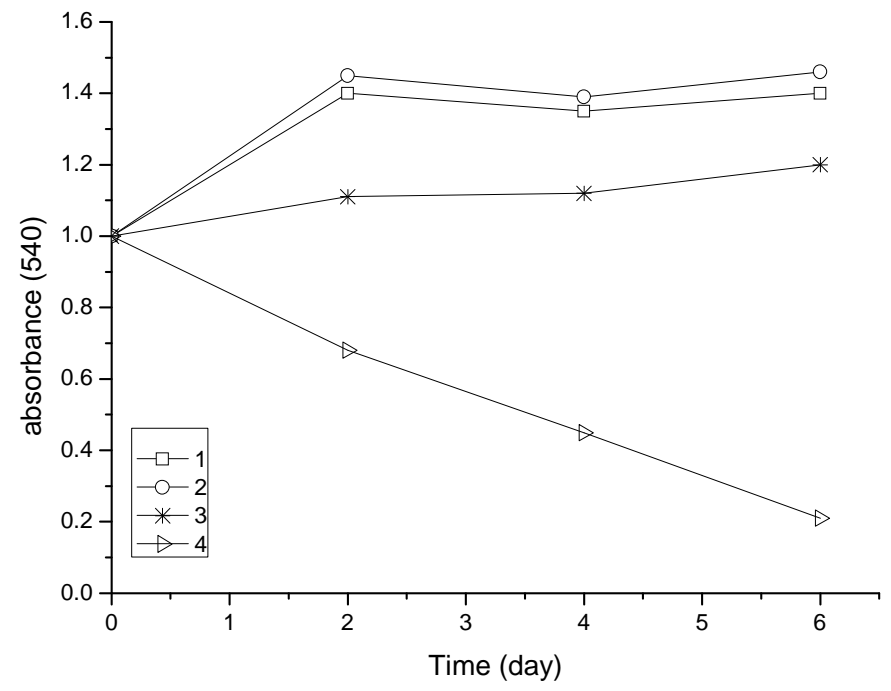

B

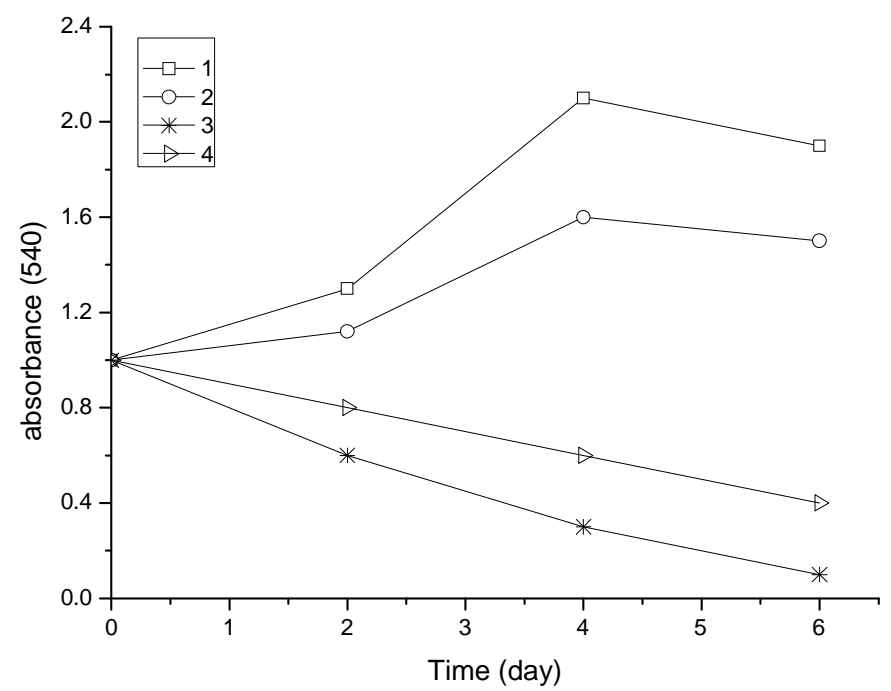

Figure 1: Proliferation and survival in rat glioma cell lines (C6) and normal human astrocytes (NHA). The MTT assay was done $0,2,4,6$ days after treatment. A, NHA cells. B, C6 cells. (1. blank; 2. SHP; 3. SHP+ radiation; 4. radiation alone). 

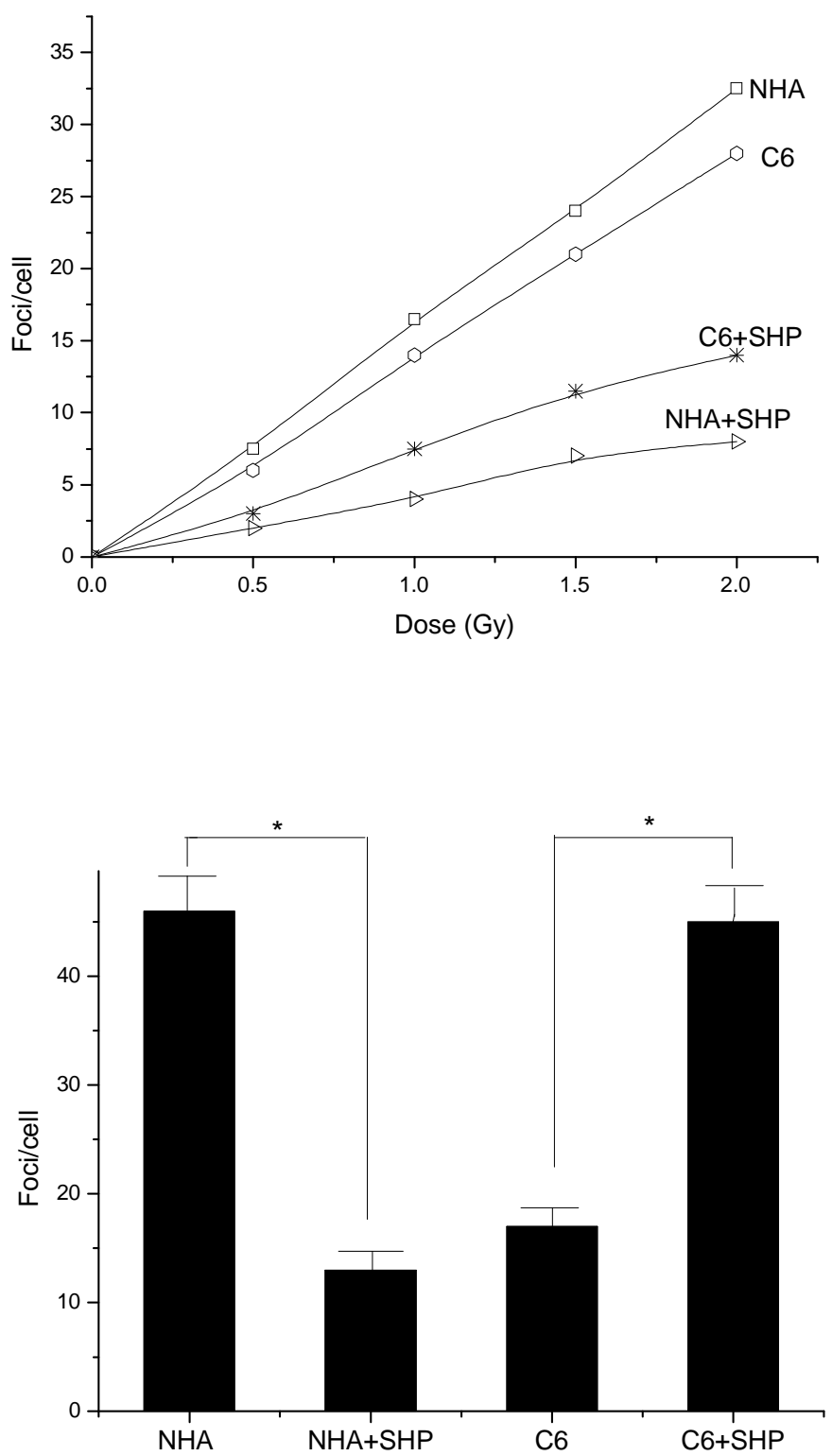

Figure 2: Phosphorylated H2AX foci in the rat glioma cell lines (C6) and in normal human astrocytes (NHA). As shown in figure A, measured at $0.5,4,8$, and $24 \mathrm{~h}$ after irradiation with $2 \mathrm{~Gy}$. Data are expressed as mean foci per cell, based on counting at least 150 cells per dose point. As shown in figure $\mathrm{B}$, quantification of the number of $\gamma \mathrm{H} 2 \mathrm{AX}$ foci by immunofluorescent analysis in NHA and C6 cells at $36 \mathrm{~h}$ after irradiation with 2 Gy. *, difference is statistically significant $(\mathrm{P}<0.005)$.

However, SHP pretreatment further increased the number of residual $\gamma \mathrm{H} 2 \mathrm{AX}$ foci in $\mathrm{C} 6$, and continued to increase steadily up to $24 \mathrm{hr}$. Higher amounts of $\gamma \mathrm{H} 2 \mathrm{AX}$ foci were observed in $\mathrm{C} 6$ compared with NHA cells $(\mathrm{P}<0.005)$. The remaining foci at $24 \mathrm{hr}$ are thought to represent unrepairable damage, which occurred at a rate of approximately two lesions per cell per 
gray. The data indicate that in C6 cells, more DSBs were produced in C6 and left unrepaired, whereas in NHA cells, less DSBs were produced and/or were subject to repair. The data are in line with the enhanced sensitivity of C6 cells compared with NHA cells.

\section{Express of DNA-Dependent Protein Kinase and Survivin}

DNA-PK activity has been shown to be essential for DNA repair and cell survival, previous studies have demonstrated that loss of function of survivin or DNA-PK results in increased cellular sensitivity to DNA-damaging agents (Meek et al, 2004; Karimi-Busheri et al., 2007). Survivin can enhance tumor cell survival upon radiation exposure by enhancement of double-strand DNA break repair (Chakravarti et al., 2004; Djuzenova et al.,2007). To investigate whether SHP plus radiation affected the expression level of phosphorylated proteins in DNA-PK and survivin, Western blot analysis was performed using antibodies raised against survivin and DNA-PK. As shown in Figure 3, SHP pretreatment strongly inhibited the DNA-PK phosphorylation and downregulated the level of survivin protein in C6 in a time-depdendent manner (Figure 3A), and difference responder in NHA cells, phosphorylation of DNA-PK was strongly increased by irradiation in a time-depdendent manner, non-significant expression of survivin in the whole course (Figure 3B ).

$\mathbf{A}$

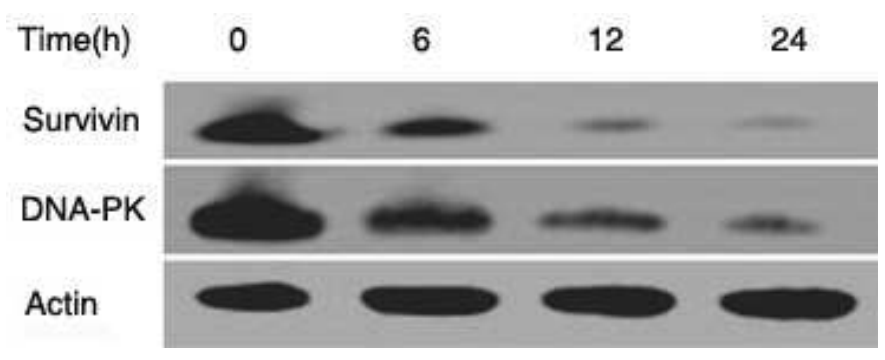

B

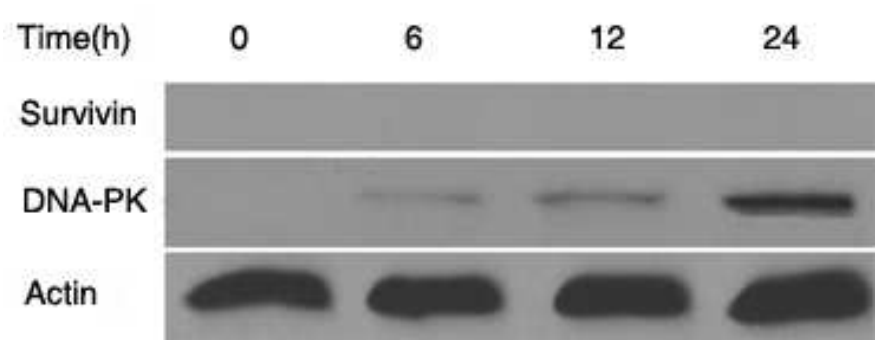

Figure 3: Expression of Survivin and DNA-PK in rat glioma cell lines (C6) and normal human astrocytes (NHA) treated with SHP and 2Gy of radiation, by using the Western blot assay. A, C6 cells B, NHA cells

\section{Apoptosis in C6 and NHA Cell Lines}

Cells apoptosis was performed by flow cytometric analysis (Table 1). Treatment of SHP combined radiation induced an increase in the sub-G0/G1 peak in C6 and NHA $(\mathrm{P}<0.01)$, an indicator of apoptosis cells, which caused a significant increase in the percentage of C6 cells in G0/G1-phase and a modest increase in cells in S phase. By comparison, the cell 
cycle distribution of the NHA cells appeared to be little affected by SHP combined radiation treatment. Apoptosis rate in C6 is significantly higher than that in NHA $(\mathrm{P}<0.01)$. Survivin is expressed in the $\mathrm{G} 2 / \mathrm{M}$ phase of the cell cycle in a cycle-regulated manner, however, it looks like the decrease and increase in survivin levels in NHA and C6 cells respectively fall short of transformation through the cell cycle. Perhaps SHP presents more complicated mechanism and causes the change of cell cycle.

Table 1: Effects of Radio or/and Shenghe Powder on Cell Cycle and Apoptosis in C6 and NHA Cell Lines by FCM(\%)

\begin{tabular}{|c|c|c|c|c|c|}
\hline \multirow{2}{*}{ Cell Lines } & \multirow{2}{*}{ Groups(mol/L) } & \multicolumn{3}{|c|}{ Distribution of cell cycle } & \multirow{2}{*}{$\begin{array}{l}\text { Apoptosis rate } \\
(\%)\end{array}$} \\
\hline & & $\mathrm{G}_{0} / \mathrm{G}_{1}$ & $\mathrm{~S}$ & $\mathrm{G}_{2} \mathrm{M}$ & \\
\hline \multirow[t]{4}{*}{ NHA } & Control & $51.8 \pm 3.3$ & $38.2 \pm 3.5$ & $10.0 \pm 0.9$ & - \\
\hline & SHP & $52.1 \pm 3.2$ & $37.9 \pm 3.4$ & $10.0 \pm 0.8$ & - \\
\hline & radio & $88.2 \pm 3.2 * *$ & $6.8 \pm 0.6^{* *}$ & $5.0 \pm 1.2 *$ & 90.1 \\
\hline & SHP+radio & $68.5 \pm 3.9^{*}$ & $25.8 \pm 3.7 *$ & $5.7 \pm 0.6^{*}$ & 32.5 \\
\hline \multirow[t]{4}{*}{ C6 } & Control & $46.8 \pm 2.3$ & $40.2 \pm 4.1$ & $13.0 \pm 1.5$ & - \\
\hline & SHP & $60.4 \pm 4.1 *$ & $30.1 \pm 3.2 *$ & $9.5 \pm 0.8$ & 15.4 \\
\hline & Radio & $79.5 \pm 3.7 * *$ & $15.6 \pm 3.6^{* *}$ & $4.9 \pm 0.7 * *$ & 72.9 \\
\hline & SHP+radio & $85.6 \pm 3.6^{*}$ & $7.1 \pm 0.5^{* *}$ & $7.3 \pm 1.1 *$ & 82.3 \\
\hline
\end{tabular}

Compared with black control group at corresponding time divisions, $* \mathrm{P}<0.01 ; * * \mathrm{P}<0.005$

\section{Discussion}

High-grade glioma remain virtually incurable with current therapeutic regimens, despite considerable advances during the last two decades in neurosurgical techniques, radiation, and chemotherapy, treatment of malignant gliomas remains mostly palliative, median survival is about 1 year from the time of diagnosis (Arslan et al., 2006; Sathornsumetee and Rich, 2006). To enhance the effects of radiation, two major strategies have been proposed. The first approach is based on the reduction of the treatment volume, the second strategy makes use of the increase of the differential response between the tumor and normal tissue to, for example, chemotherapeutic drugs, biologic agents, and genetic or proteomic techniques (Muni et al.,2010; Bidros et al.,2010; Both,2009). However, complex molecular determinants of tumor response to radiation have limited the success of these approaches to date. Obviously, it is important to find a more effective approach which would be to develop agents that selectively sensitize these glioma cells to radiation.

We previously demonstrated that Shenghe powder could induce tumor cells apoptosis and reverse multidrug resistance (Wang et al., 2007), inhibit the proliferation of C6 and decrease malignant degree (Xia et al., 2007), improve the survival time of the patients with postoperative high-grade glioma (Xia, 2005). Its complex components may offer a novel antitumor mechanism. The objective of this study was to determine the effect of Shenghe powder on the repair of DNA damage induced by radiation. Radiation causes a broad spectrum of DNA lesions such as alkali-labile lesions, single-strand breaks and DSBs. DSBs is the major threat to the genomic integrity of cells, which is biologically the most significant lesion produced by radiation and other exogenous cytotoxic agents (Lavin et al.,2005; Singh et al.,2009; Sarcar et al.,2010 ). It has been shown that histone $\mathrm{H} 2 \mathrm{AX}$ becomes phosphorylated immediately after irradiation, which in turn is believed to recruit DNA repair factors to sites of DNA double-strand breaks (Kanaar et al., 1998; Momota et al.,2003). Because $\gamma \mathrm{H} 2 \mathrm{AX}$ is closely associated with DNA double-strand break repair mechanisms, we studied the radiation response of C6 and NHA lines in vitro, using $\gamma \mathrm{H} 2 \mathrm{AX}$ expression as a marker of DNA double-strand breaks. Of the various techniques currently 
available to assay double-strand breaks, we chose an immunofluorescence approach involving quantification of phosphorylation of histone $\mathrm{H} 2 \mathrm{AX}$ because of its sensitivity, which can be readily detected by fluorescent immunostaining with antibodies to the phosphorylated form of the protein. The fluorescent intensity correlates well with the number of DNA double-strand breaks (Sedelnikova et al.,2002). This research showed that Shenghe powder enhanced radiosensitivity of C6 cells, the pre-treatment with Shenghe powder resulted in reduced numbers of $\gamma \mathrm{H} 2 \mathrm{AX}$ foci in irradiated C6 cells, the capacity of repair was markedly decreased. In contrast, Shenghe powder could depress the radiation-induced DNA double-strand break and enhance the DNA repair capacity in NHA.

DNA-PK is overexpressed in brain glioma, it has been firmly established that DNA-PK plays an important role in DNA end joining, especially DNA double-strand break repair after radiation, prior reports have shown that inhibition or deficiency in DNA-PK leads to decreased DNA double-strand break repair and increased radiosensitivity both in vitro and in vivo (Meek et al., 2004; Veuger et al.,2003; Chaudhry et al.,2010; Burdak-Rothkamm et al.,2007). The repair of DNA double-strand breaks after radiation may account for the poor apoptotic response and ultimate radioresistance of malignant glioma cells. This study showed that Shenghe powder pretreatment strongly inhibited the DNA-PK phosphorylation, downregulated the level of DNA-PK in a time-depdendent manner in C6 cells. Nevertheless, DNA-PK was strongly increased in NHA. It suggested that Shenghe powder improved the radioresistance of NHA and enhance radiosensitivity of C6 cells which correlated with DNA-PK phosphorylation.

Survivin is a novel member of the inhibitor of apoptosis (IAP) family, which is located on human chromosome $17 \mathrm{q} 25.3$, encoding a $16.5-\mathrm{kDa}$ protein comprising amino acids. Survivin is the smallest member of the mammalian IAP family, which is highly expressed in the $\mathrm{G}_{2} / \mathrm{M}$ phase of the cell cycle, which enhances survival of tumor cells primarily through suppression of apoptotis-related cell death perhaps via direct inhibition of caspase-related proteins (Dohi et al.,2004; Shin et al.,2001). Survivin may enhance tumor cell survival upon radiation exposure such as regulation of double-strand DNA break repair and tumor cell metabolism, which were most evident in the radiation-resistant cell lines (Shirai et al.,2009; Ogura et al.,2008). Uniform, Survivin expression is associated with glioma progression from low-to high grade, which appeared to be a marker for radiation resistance, with strongest expression in radiation-resistant glioma phenotypes (Zhen et al.,2005; Jiao et al.,2004). Further, radiation appeared to increase levels of surviving (Chakravarti et al.,2004). In the presence of radiation, Survivin appears to enhance double-strand DNA breaks repair, suppressing radiation induced cell death; thereby suppressing the expression of survivin is indispensable, which plays a crucial role in tumorigenesis and progression of glioma (Saito et al.,2008; Söling et al.,2007). This study showed that SHP pretreatment strongly inhibited the expression of survivin in C6 in a time-depdendent manner.

As the biological underpinnings of such phenomena as radioresistance are often multi-rather than unifaceted. the multiple factors focus on seeking multi-approach to enhance radiosensitivity of glioma, include down-regulation resistance genes or up-regulation of target genes. Shenghe powder, its complex components may offer multitarget treatment, which anastomose to requirement of multi-approach treatment in glioma.

In conclusion, our studies revealed that Shenghe powder had a novel bidirectional function: (1) Shenghe powder diminished the formation of $\gamma \mathrm{H} 2 \mathrm{AX}$ foci in $\mathrm{C} 6$ cells exposed to radiation, decreased the capacity of DNA repair, enhanced radiosensitivity of C6 cells, which correlated with the changed of DNA-PK and survivin. (2) Shenghe powder increased the DNA-PK phosphorylation, improved the radioresistance of normal human astrocytes and prevented the normal astrocytes from radiation.

\section{Acknowledgments}

This work was supported by Health Science Foundation of Shanxi (200914). 


\section{References}

1. Arslan, M., Karadeniz, A.N., Aksu, G., Guveli, M., Fayda, M., Dogan, A.K. and Akyuz, F.(2006).Postoperative hypofractionated radiotherapy in glioblastoma multiforme. J. B.U.ON.. 11:39-42.

2. Bidros, D.S., Liu, J.K. and Vogelbaum, M.A.(2010). Future of convection-enhanced delivery in the treatment of brain tumors. Future Oncol.. 6:117-125.

3. Both, G.W.(2009). Recent progress in gene-directed enzyme prodrug therapy: an emerging cancer treatment. Curr. Opin. Mol. Ther.. 11:421-432..

4. Burdak-Rothkamm, S., Short, S.C., Folkard, M., Rothkamm, K. and Prise, K.M.(2007). ATR-dependent radiation-induced gamma $\mathrm{H} 2 \mathrm{AX}$ foci in bystander primary human astrocytes and glioma cells. Oncogene. 26: 993-1002.

5. Camphausen, K., Burgan, W., Cerra, M.(2004). Enhanced radiation-induced cell killing and prolongation of $\gamma \mathrm{H} 2 \mathrm{AX}$ foci expression by the histone deacetylase inhibitor MS-275. Cancer Res.. 64: 316-321.

6. Chakravarti, A., Zhai, G.G. and Zhang, M.(2004). Survivin enhances radiation resistance in primary human glioblastoma cells via caspase-independent mechanisms. Oncogene. 23: 7494-7506.

7. Chaudhry, M.A., Sachdeva, H. and Omaruddin, R.A.(2010). Radiation-induced micro-RNA modulation in glioblastoma cells differing in DNA-repair pathways. DNA Cell Biol.. 29:553-561.

8. Clarke, J.L., Iwamoto, F.M., Sul, J., Panageas, K., Lassman, A.B., DeAngelis, L.M. and Hormigo,A.(2009). Randomized phase II trial of chemoradiotherapy followed by either dose-dense or metronomic temozolomide for newly diagnosed glioblastoma. J.Clin.Oncol.. 27:3861-3867.

9. Djuzenova, C.S., Güttler, T., Berger, S., Katzer, A. and Flentje M.(2007). Differential response of human glioblastoma cell lines to combined camptothecin and ionizing radiation treatment. Cancer Biol. Ther.. 7:364-373.

10. Dohi, T., Beltrami, E., Wall, N.R., Plescia, J. and Altieri, D.C.(2004). Mitochondrial survivin inhibits apoptosis and promotes tumorigenesis. J. Clin. Invest.. 114: 1117-1127.

11. Entin-Meer, M., Yang, X. And VandenBerg, S.R.(2007). In vivo efficacy of a novel histone deacetylase inhibitor in combination with radiation for the treatment of gliomas. Neuro. Oncol.. 9:82-88.

12. Fogh, S.E., Andrews, D.W., Glass, J., Curran, W., Glass, C. and Champ, C. (2010).Hypofractionated stereotactic radiation therapy: an effective therapy for recurrent high-grade gliomas. J.Clin.Oncol.. 28:3048-3053

13. Jiao, B.H., Yao, Z.G., Geng, S.M. and Zuo, S.H.(2004). Expression of survivin, a novel apoptosis inhibitor and cell cycle regulatory protein, in human gliomas. Chin. Med. J.. 117:612-614.

14. Kanaar, R., Hoeijmakers, J.H.J. and van Gent, D.C.(1998). Molecular mechanisms of DNA double-strand break repair. Trends Cell Biol.. 8:483-489.

15. Karimi-Busheri, F., Rasouli-Nia, A., Allalunis-Turner, J. and Weinfeld M.(2007). Human polynucleotide kinase participates in repair of DNA double-strand breaks by nonhomologous end joining but not homologous recombination. Cancer Res.. 67: 6619-6625.

16. Lavin, M.F., Birrell, G. and Chen, P.(2005). ATM signaling and genomic stability in response to DNA damage. Mutat. Res.. 569: 123-132.

17. Mah, L.J.,El-Osta, A. and Karagiannis, T.C.(2010). $\gamma \mathrm{H} 2 \mathrm{AX}$ : a sensitive molecular marker of DNA damage and repair. Leukemia. 24: 679-686.

18. Manti, L. and D'Arco, A.(2010). Cooperative biological effects between ionizing radiation and other physical and chemical agents. Mutat. Res.. 704: 115-122.

19. Meek, K., Gupta, S., Ramsden, D.A.(2004). The DNA-dependent protein kinase: The director at the end. Immunol. 
Rev.. 200:132-141.

20. Momota, H., Ichimiya, S. and Kondo, N.(2003). Histone H2AX sensitizes glioma cells to genotoxic stimuli by recruiting DNA double-strand break repair proteins. Int. J. Oncol.. 23: 311-315.

21. Muni,R., Minniti, G., Lanzetta, G. and Caporello, P.(2010). Short-term radiotherapy followed by adjuvant chemotherapy in poor-prognosis patients with glioblastoma. Tumori. 96:60-64.

22. Ogura, A., Watanabe, Y. and lizuka, D.(2008). Radiation-induced apoptosis of tumor cells is facilitated by inhibition of the interaction between Survivin and Smac/DIABLO. Cancer Lett.. 259: 71-81.

23. Saito, T., Hama, S., Izumi, H., Yamasaki, F., Kajiwara, Y., Matsuura, S. And Kurisu, K.(2008). Centrosome amplification induced by survivin suppression enhances both chromosome instability and radiosensitivity in glioma cells. Br. J. Cancer. 98:345-355.

24. Sarcar, B., Kahali, S. And Chinnaiyan, P.(2010). Vorinostat enhances the cytotoxic effects of the topoisomerase I inhibitor SN38 in glioblastoma cell lines. J. Neurooncol.. 99:201-207.

25. Sathornsumetee, S. and Rich, J.N.(2006). New treatment strategies for malignant gliomas. Expert. Rev. Anticancer Ther.. 6: 1087-1104.

26. Sedelnikova, O.A., Rogakou, E.P., Panyutin, I.G. and Bonner, W.M.(2002). Quantitative detection of (125)IdU-induced DNA double-strand breaks with gamma-H2AX antibody. Radiat. Res.. 158: 486-492.

27. Shin, S., Sung, B.J., Cho, Y.S.(2001). An anti-apoptotic protein human survivin is a direct inhibitor of caspase-3 and -7 . Biochemistry. 40: 1117-1123.

28. Shirai, K., Suzuki, Y., Oka, K., Noda, S.E. and Katoh H. (2009). Nuclear survivin expression predicts poorer prognosis in glioblastoma. J. Neurooncol.. 91:353-358.

29. Singh, S.K., Wu, W. Wang, M. and Iliakis, G.(2009). Extensive repair of DNA double-strand breaks in cells deficient in the DNA-PK-dependent pathway of NHEJ after exclusion of heat-labile sites. Radiat. Res.. 172:152-164.

30. Söling, A., Plugge, EM., Schmitz, M., Weigle, B., Jacob, R., Illert, J. Holzhausen, H.J. and Rainov, N.G.(2007).Autoantibodies to the inhibitor of apoptosis protein survivin in patients with brain tumors. Int. J. Oncol.. 30: 123-128.

31. Stupp, R., Hegi, M.E., Gilbert, M.R. and Chakravarti, A.(2007). Chemoradiotherapy in malignant glioma: standard of care and future directions. J.Clin.Oncol.. 25: 4127-4136.

32. Veuger, S.J., Curtin, N.J., Richardson, C.J., Smith, G.C. and Durkacz, B.W.(2003). Radiosensitization and DNA repair inhibition by the combined use of novel inhibitors of DNA-dependent protein kinase and poly(ADP-ribose) polymerase-1. Cancer Res.. 63: 6008-6015.

33. Wang, J., Xia, Y., Wang, H. and Hou, Z.(2007). Chinese Herbs of Shenghe Powder Reverse Multidrug Resistance of Gastric Carcinoma SGC-7901. Integr. Cancer Ther.. 6: 400-404.

34. Xia Y. (2005). Role of Shenghe Powder in Radiation on malignant glioma after surgery. J. G.M. Tradit. Chinese Med.. 20:50-51.

35. Xia,Y., Wang, J., Wu, Y. and Wang, H.(2007). Inducing differentiation effect of Shenghe Powder on C6 brain glioma cells. Lishizhen Med. Materia. Medica. Res.. 18:290-291.

36. Zhen, H.N., Zhang, X. and Hu, P.Z. (2005). Survivin expression and its relation with proliferation, apoptosis, and angiogenesis in brain gliomas. Cancer. 104: 2775-2783. 